\title{
The Branching Pattern of the Aortic Arch in Gallus Domesticus
}

\author{
Irina ROMAN, Cristian MARTONOS*, Cristian DEZDROBITU, Alina BERLEA, Iulia PREJA, Alexandra \\ IRIMIE, Raluca FLOCEA, Ioana CHIRLEAN, Alexandru GUDEA, Florin STAN, Aurel DAMIAN \\ ${ }^{1}$ Faculty of Veterinary Medicine, Univerity of Agricultural Sciencies and Veterinary Medicine, Cluj- Napoca. \\ *Coresponding author: cristian.martonos@usamvcluj.ro
}

Bulletin UASVM Veterinary Medicine 77(2)/2020

Print ISSN 1843-5270; Electronic ISSN 1843-5378

doi:10.15835/buasvmcn-vm:2020.0039

\begin{abstract}
In birds, in contrast to mammals, two brachiocephalic trunks are the origin in the arch of aorta and give rise to the subclavian arteries and common carotid. The aim of this study was to investigate the vascular branching morphology of the aortic arch in Gallus Domesticus with the purpose of providing accurate data with regards to the arterial supply of these segments to researchers and clinicians. The biological material was represented by 10 adult chicken bodies with an average weight of $2 \mathrm{~kg}$, females. After procurement of the biological material, the feathers, skin, muscles and sternum were removed for easy access to the heart. After left ventricular cannulation, epoxy resin mixed with red dye was injected. The body was immersed in 5\% formaldehyde for 24 hours. Next, stratigraphic dissection was performed. Two brachiocephalic trunks branched continually from aortic arch caudoventral to the primary bronchi. The left subclavian artery gave rise to sternoclavicular, thoracic, axillary and intercostal and the same was observed to the right side. Due to this method we could observe the aortic arch of Gallus Domesticus being different from mammals in that the left and right brachiocephalic trunks are detached from it.
\end{abstract}

Keywords: Aortic arch, arterial, birds.

\section{Introduction}

Studying the literature, with regards to the anatomical aspects of the arterial tree distribution, it was observed that existing findings generally follow the description and distribution of the aorta (Erdogan, 2012) and the main visceral trunks.

While similar vascular organization can exist between species, variations in vascularization can also appear among individuals of the same species. Attempts to understand vascular organization using different morphological approaches will facilitate recognition of patterns of speciesspecific vascularization and the variations found among species. (Erdogan and Kilınc, 2014)

The bird's cardiovascular system is often addressed for the study of atherosclerosis, a 2014 area in which the coronary arteries and the aorta are studied in particular (Glanny, 1940).
The literature also has data on the embryonic development of the cardiovascular system of several species of birds (Glenny, 1955).

Regarding the studied species, the literature has shown a variety of topographic, origin and distribution differences of the arterial supply compared to mammals, although they are not fully identified (Abdel-Magied, 1978).

The aim of this article is the macroscopical study of the arterial supply of the wings and limbs of Gallus domesticus, with the purpose of providing accurate data with regards to the arterial supply of these segments to researchers and clinicians.

\section{Materials and methods}

The biological material was represented by 10 adult chicken bodies with an average weight of 
$2 \mathrm{~kg}$, females, from the Parasitology Clinic of the Faculty of Veterinary Medicine, Cluj-Napoca.

After procurement of the biological material, the feathers, skin, muscles and sternum were removed for easy access to the heart. After left ventricular cannulation, epoxy resin mixed with red dye was injected (Figure 1). Afterwards, a ligature of the aorta was performed in order to avoid return of the substance to the ventricular cavity. The body was immersed in $5 \%$ formaldehyde for 24 hours. Next, stratigraphic dissection was performed to highlight the arterial vessels in order to photograph and describe them.

\section{Results and discussions}

Following stratigraphic dissection, the ascending aorta (Arteria aortes ascendens) was first examined, with the origin in the left ventricle. After a short trajectory, the aorta continues with the aortic arch (Arcus aortae). From the cranial margin of the aortic arch, two brachiocephalic trunks emerge. Their origin is found ventrally to the syrinx and caudally to the primary bronchi. First, the left brachiocephalic trunk (Truncus bra- chiocephalicus sinister) emerges, followed by the right brachiocephalic trunk (Truncus brachiocephalicus dexter).

Following a short dorso-cranial trajectory, each brachicephalic trunk divides into a common carotid artery and a subclavian artery. Thus, the left brachiocephalic trunk divides into the left subclavian artery (Arteria subclavicularis sinister) and the left common carotid artery (Arteria carotis comunis sinister), while the right brachiocephalic trunk divides (Figure 2) into the right subclavian artery (Arteria subclavicularis dexter) and the right common carotid artery (Arteria carotis comunis dexter).

Each subclavian artery divides into a sternoclavicular artery (Arteria sternoclavicularis), an internal thoracic artery, intercostal arteries and an axillary artery. The axillary artery is the first arterial branch of the wing (Figure 3).

Subsequently, the left subclavian artery branches into the sternoclavicular artery, the thoracic artery (Arteria thoracica), the axillary artery (Arteria axilaris) and the intercostal arteries (Arteria intercostalis) (Figure 4).

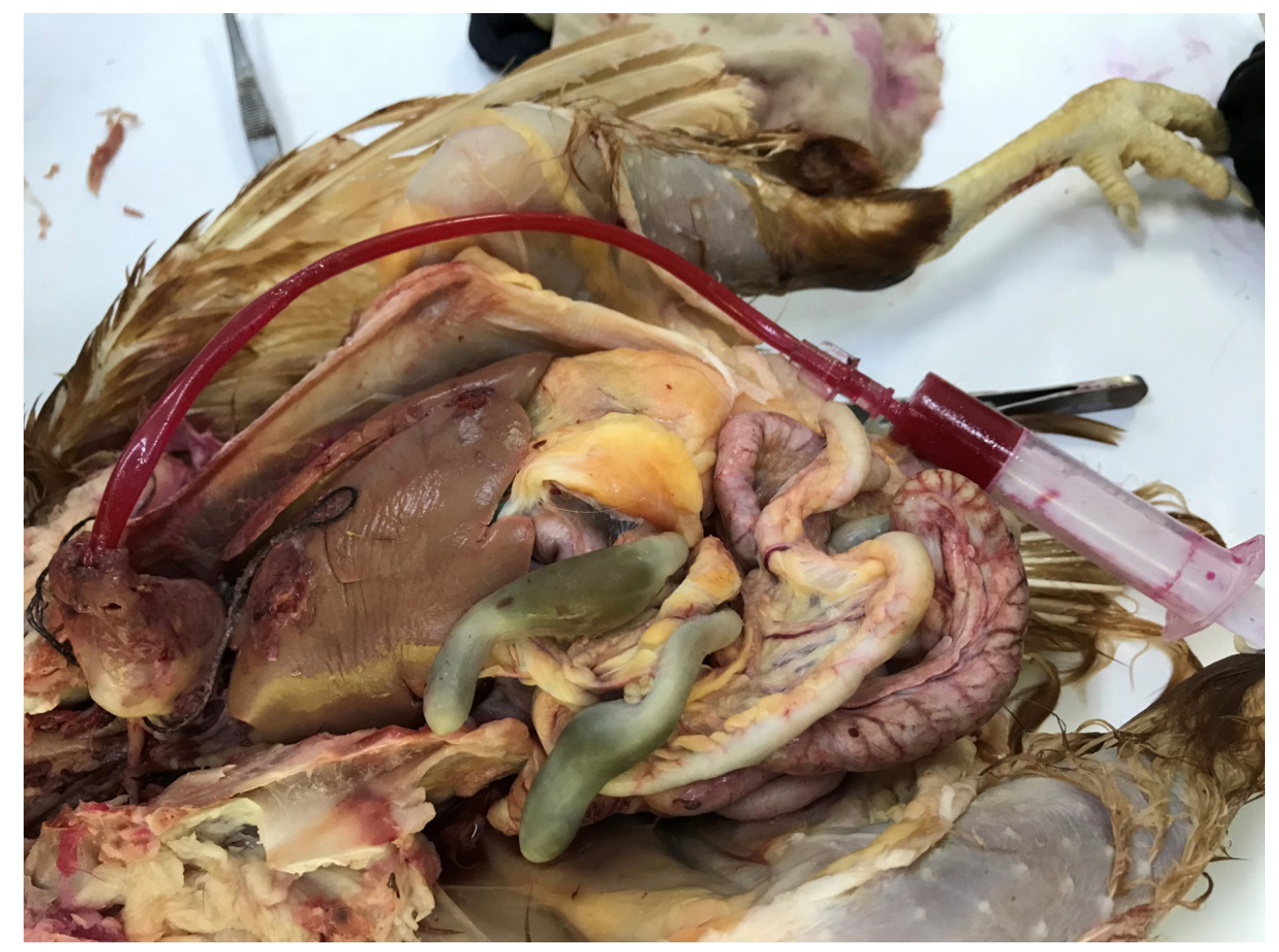

Figure 1. Material and method 


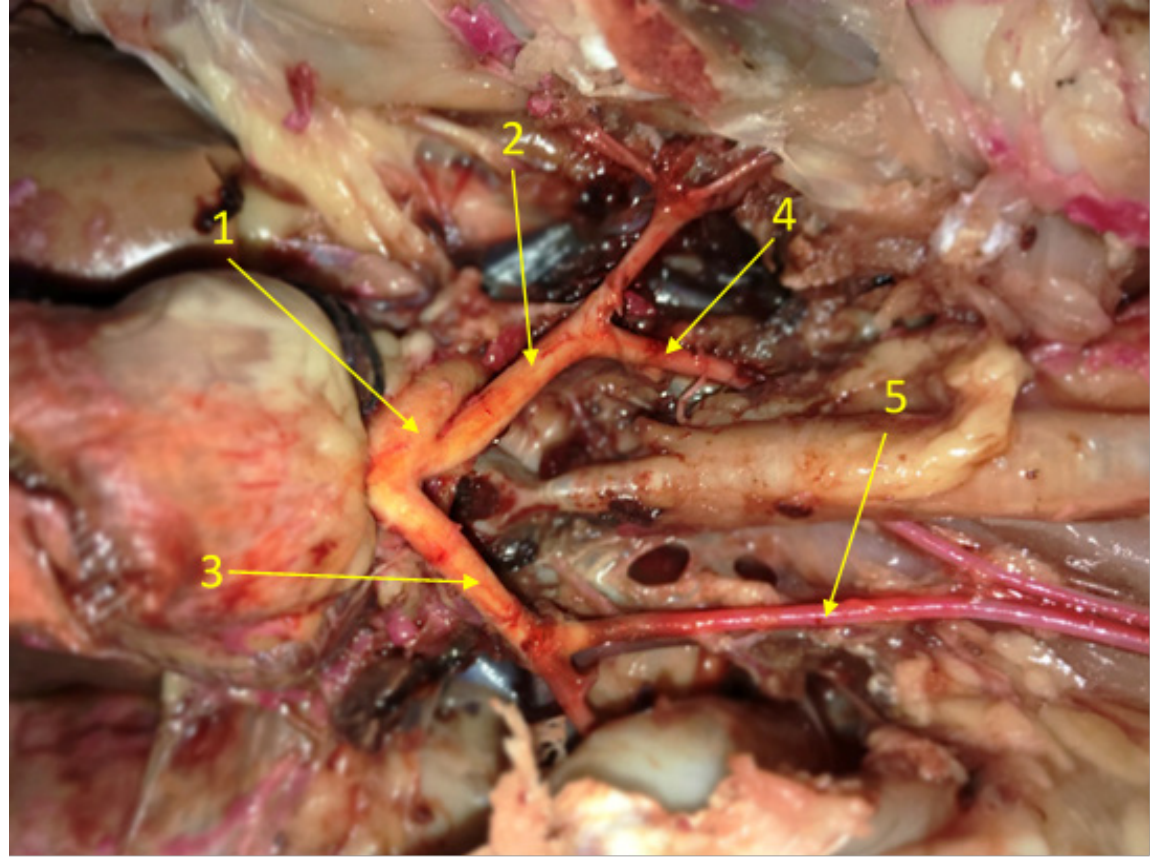

Figure 2: The aortic arch:

1. Aortic cross, 2. Left brachiocephalic trunk, 3. Right brachiocephalic trunk, 4. Left comon carotid artery, 5 Right common carotid artery.

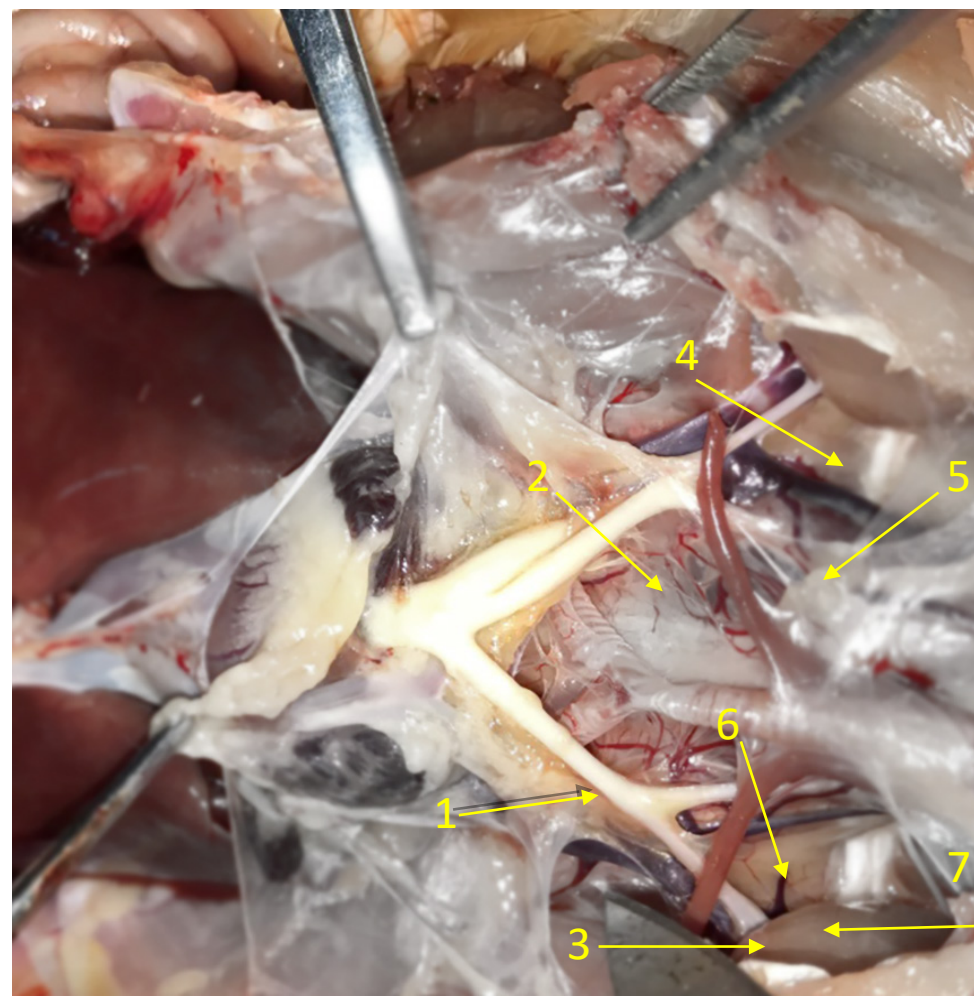

Figure 3. Brachiocephalic arterial trunks:

1. Right brachiocephalic arterial trunk; 2. Left brachiocephalic arterial trunk; 3. Right subclavian artery; 4. Left subclavian artery;

5. Left common carotid artery; 6. Right common carotid artery. 7. Sternotrachealis muscle 


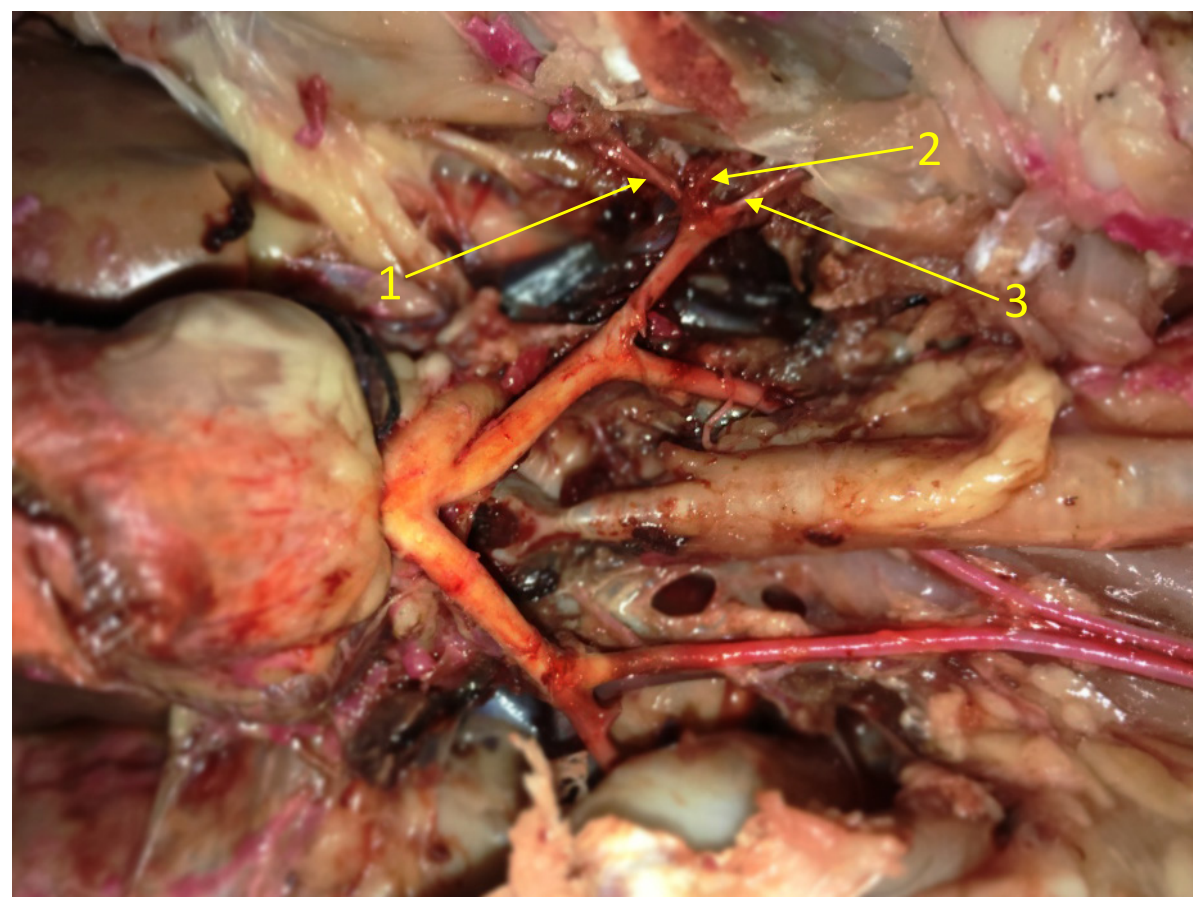

Figure 4. Subclavian artery terminals:

1. Thoracic artery; 2. Axillary artery; 3. Sternoclavicular artery.

Glenny (1953a) was observed the first branch of the subclavian artery as the coracoid or sternoclavicular artery in the birds of the Apodiformes family. This study also reported that the second branch of the subclavian artery is the pectoral trunk, and that the axillary artery is a continuation of the subclavian artery, the branches originating from subclavian artery were ramified in the almost same level as in the long-legged buzzard.

Glenny $(1948 a, 1948 b)$ was shown to originate from the subclavian artery. Once more, the coracoid major artery give rise from the subclavian artery and the coracoid minor artery are the origin in the axillary artery are also reported in species of the Coliiformes family. Glenny observed in 1951 and 1942, that the sternoclavicular artery is not present in birds belonging to the Fringillidae.

Glanny has shown the internal and external thoracic arteries are presented to branch off from the subclavian artery in Gruiformes (Glenny 1947), Coliiformes (Glenny 1944), Passeriformes (Glenny 1945a, 1945b) and Trogoniformes (Glenny1948a) families.

\section{Conclusion}

The aortic arch provides to the right of the median plane. The brachiocephalic trunks supply the wings, particularly the flight muscles, the neck and the head. Both trunks give off the common carotid artery (a. carotis communis) and continue as the subclavian artery (a. subclavia). The short common carotid artery extends to the origin of the vertebral trunk (truncus vertebralis), then continues as the internal carotid artery (a. carotis interna). The subclavian arteries' trajectory is short and divides terminally into: the sternoclavicular artery, the axillary artery and the thoracic artery.

Acknowledgments. This research did not receive any specific grant from funding agencies in the public, commercial, or not-for-profit sectors.

\section{References}

1. Abdel-Magied EM, King AS (1978). The topographical anatomy and blood supply of the carotid body region of the domestic fowl, Department of Veterinary Anatomy, University of Liverpool, J. Anat.,126, 3, pp. 535-546.

2. Erdogan and Kilinc (2014). The branching pattern of the aortic arch in the long-legged buzzard (Buteo rufinus Cretzschmar 1829). Anat Sci Int (2014) 89:151-155.

3. Erdogan S (2012). The branching of the aortic arch in the Eurasian bittern (Botaurus stellaris, Linnaeus 1758). Vet Med Czech 57(5):239-244.

4. Glenny FH (1940). A systematic study of the main arteries in the region of the heart-aves, Part I. Belted kingfisher (Ceryle alcyon) L., Green heron (Butorides virescens 
virescens) L., Great blue heron (Ardea herodias herodias) L., American bittern (Botaurus lentiginosus) Mont. Anat Rec 76(4):371-380.

5. Glenny FH (1942). A systematic study of the main arteries in the region of the heart-aves III: Fringillidae, Part 1. Ohio J Sci 42(2):84-90.

6. Glenny FH (1944). A systematic study of the main arteries in the region of the heart-aves IX: Coliiformes, Part 1. Ohio J Sci 44:273-276.

7. Glenny FH (1945a). A systematic study of the main arteries in the region of the heart-aves XXI: Passeriformes-Paridae, Part 1. Ohio J Sci 45(1):19-21.

8. Glenny FH (1945b). A systematic study of the main arteries in the region of the heart-aves XV: Gaviiformes, Part 1. Ohio J Sci 45(4):167-169.
9. Glenny FH (1947). A systematic study of the main arteries in the region of the heart-aves XVI: Gruiformes, Part 1. Auk 62:266-269.

10. Glenny FH (1948a). A systematic study of the main arteries in the region of the heart-aves IV: Trogoniformes, Part 1. Auk 60:235-239.

11. Glenny FH (1948b). A systematic study of the main arteries in the region of the heart-aves XVI: Charadriiformes, Part 1. Ohio J Sci 48(5):194-198.

12. Glenny FH (1951). A systematic study of the main arteries in the region of the heart-aves XVII: Psittaciformes, Part 1. Ohio J Sci 51(6):347-352.

13. Glenny FH (1953). A systematic study of the main arteries in the region of the heart-aves XIX: Apodiformes, Part 1. Ohio J Sci 53(6):367-369. 